\title{
LA DISPUTA POR LA HOMOLOGACIÓN DE LOS PROCESOS ELECTORALES EN CHIAPAS
}

\author{
Álvaro F. López Lara \\ María Eugenia Reyes Ramos
}

Resumen: En este trabajo nuestra meta es analizar las decisiones y estrategias de los actores políticos en torno al proceso de reforma para homologar el calendario electoral en Chiapas. Este caso muestra que aunque las reformas para homologar los procesos son deseables, su realización moviliza ambiciones de los poderes locales e incrementan las tensiones institucionales.

Palabras clave: legislaturas, reforma electoral, diputados, Chiapas.

Enviado a dictamen: 27 de agosto de 2008. Aprobación: 05 de noviembre de 2008.

Dr. Álvaro F. López Lara, profesor-investigador del Departamento de Relaciones Sociales, Universidad Autónoma Metropolitana-Xochimilco, correo electrónico: 1laf4385@correo.xoc.uam.mx.

Dra. María Eugenia Reyes Ramos, profesora-investigadora del Departamento de Relaciones Sociales, Universidad Autónoma Metropolitana-Xochimilco, correo electrónico: mereyes@correo.xoc.uam.mx.
Abstract: In this work our goal is to analyze the decisions and strategies of the political actors around the reform process and the electoral cycle in Chiapas. The case of Chiapas shows that the reforms to promote concurrent elections mobilize ambitions of the local powers and increase institutional tensions.

Key words: legislature, electoral reform, congressman, Chiapas.

L a homologación del calendario electoral en los estados para sincronizarlo con las elecciones federales es una de las nuevas vertientes de las reformas de tercera generación. Algunos expertos suponen que las ventajas asociadas a la homologación de calendarios en los estados se verían reflejadas en un incremento de la participación electoral, una mayor capacidad ciudadana de monitoreo, la reducción de costos en la organización electoral y un mejor ambiente de negociación para los partidos que ocuparían menor tiempo en las contiendas electorales (Peschard, 2004: 80; Vergara, 2007: 16). Desde otra perspectiva, se ha argumentado que la principal desventaja de sincronizar los calendarios consiste en el efecto de arrastre de las elecciones federales y especialmente de los comicios presidenciales (Campbell, 1986) que tienden a distorsionar la competencia en los estados. ${ }^{1}$ 
Aunque diez entidades federativas han celebrado elecciones concurrentes desde el año 2000, es un hecho que la dispersión y separación del calendario siguen marcando la pauta de la división vertical del poder en el federalismo electoral mexicano. ${ }^{2}$ Por ello, a raíz de la reciente aprobación de la reforma constitucional en materia electoral, ${ }^{3}$ ha crecido el interés de los legisladores y miembros de los organismos electorales en torno a la necesidad de reducir progresivamente la dispersión y heterogeneidad de las instituciones mediante la adopción de elecciones concurrentes y de legislación más homogénea y de mayor calidad (Reyes, 2007: 18).

Las reformas tendientes a homologar los procesos electorales han sido evaluadas positivamente desde el punto de vista normativo e institucional, pues su efecto se asocia a una mayor calidad democrática en los estados. No obstante, los intentos recientes por introducir cambios en la constitución y las leyes electorales estatales demuestran que este tipo de reformas confrontan los intereses de los poderes locales y en no pocas ocasiones, provocan tensiones institucionales.

Recientemente, los congresos de Michoacán, Oaxaca y Chiapas fueron escenario de negociaciones relacionadas con la presentación de proyectos para modificar el calendario electoral a fin de sincronizarlo con las elecciones federales. En el estado de Michoacán, tras una serie de negociaciones, los diputados del Congreso local aprobaron - en el mes de febrero de 2007- una reforma que permitirá homologar las elecciones estatales con las elecciones federales intermedias de 2015. El esquema de reforma adoptado en Michoacán consistió en acortar los períodos de ejercicio de las diversas autoridades electas. Gracias a la reforma, el Gobernador del estado electo en 2007, entrará en funciones en febrero de 2008 y concluirá su período de ejercicio de cuatro años en el año 2012. Mientras el Gobernador electo en la elección de noviembre del 2011 tendrá un mandato que durará tan solo dos años y siete meses. Con la misma lógica, la reforma introdujo ajustes en la duración de los cargos de los diputados locales y los ayuntamientos para sin- cronizarlos con los comicios a celebrarse en el año 2015 (Reyes, 2007: 21).

En Oaxaca, el gobernador Ulises Ruíz presentó ante el congreso local un proyecto para homologar los comicios en el 2012, el cual incluía una cláusula para aplazar por un año las elecciones y ampliar el mandato de los diputados locales y de los ayuntamientos en funciones. El Congreso Oaxaca aprobó el proyecto el 28 de septiembre de 2006, avalando al mismo tiempo, una disposición para nombrar a un gobernador interino por un período de dos años al término de la gestión de Ruíz. Ante la decisión del Congreso del estado las dirigencias nacionales del PRD y Convergencia promovieron un recurso de inconstitucionalidad ante la Suprema Corte de Justicia de la Nación; después de revisar los argumentos invalidó las reformas y ordenó la celebración de las elecciones en las fechas previstas por la constitución estatal (El Universal;10/01/2007).

En el estado de Chiapas la presentación de la iniciativa de reforma constitucional para homologar los procesos electorales desencadenó un intenso regateo entre los actores políticos de la entidad que dirimieron sus desacuerdos conforme a los mecanismos y los puntos de veto del arreglo constitucional. Durante el lapso de un año, la decisión sobre la reforma se mantuvo en vilo. El gobernador saliente Pablo Salazar impulsó en 2006 una reforma que fue avalada por el Congreso local y la mayoría de los ayuntamientos, pero fue frenada por la resolución de la Suprema Corte de Justicia. Posteriormente, el gobernador Juan Sabines retomó la iniciativa y propuso una nueva reforma para homologar los comicios: después de dos intentos de negociación entre el gobernador y los partidos fue posible alcanzar una decisión consensual.

En este trabajo nuestra meta es analizar las decisiones y las estrategias de los actores políticos en torno al proceso de reforma a la constitución estatal. Suponemos que el análisis en profundidad sobre este caso nos permitirá observar la complejidad de los mecanismos de reforma constitucional cuando el poder se encuentra 
disperso en diferentes esferas institucionales. Adicionalmente, al analizar las secuencias de este proceso de reforma intentaremos identificar a los jugadores con poder de veto y sus estrategias dominantes. Partiendo de las proposiciones de Tsebelis (2006) caracterizaremos a los jugadores conveto institucionales que son aquellos actores colectivos o individuales especificados en la constitución (el Ejecutivo, el Congreso, Tribunales, gobiernos locales) y los jugadores con veto partidarios que son producto del sistema político y que difieren en cuanto a su número, distancias ideológicas y grado de cohesión.

\section{El calendario electoral y la división del poder en Chiapas}

En el contexto del federalismo electoral mexicano, Chiapas figura entre las entidades cuyo calendario muestra mayor dispersión, pues los comicios para los distintos cargos de autoridad en el gobierno estatal y municipal se celebran siempre en forma no-concurrente. En virtud de esta característica del timing político las elecciones federales no coinciden con las estatales, ni las elecciones para renovar la gubernatura se celebran en forma simultánea con las municipales y diputaciones locales. Tan solo entre el período de octubre de 1998 a octubre de 2007 se celebraron seis elecciones locales (octubre de 1998, 20 de agosto de 2000, 7 de octubre de 2001, 3 de octubre de 2004, 20 de agosto de 2006 y 7 de octubre de 2007) y tres federales ( 2 de julio de 2000, 6 de julio de 2003 y 6 de julio de 2006).

La celebración de elecciones separadas y no-concurrentes fue un asunto manejable durante la etapa de hegemonía del PRI, pues un solo actor se encargaba de coordinar el proceso para la renovación de los diferentes cargos. Sin embargo, a partir de que el estado de Chiapas experimenta con la democratización electoral son más evidentes las consecuencias de la dispersión del calendario en la dinámica de la competencia y en la composición de las instituciones. Desde el punto de vista de los votantes las elecciones separadas y noconcurrentes han incidido negativamente en la tasas de participación electoral que con ciertas oscilaciones (la tasa fue de $51.4 \%$ en la elección de gobernador en agosto de 2000,51.9\% en los comicios intermedios de 2001, 31.5\% en los elecciones federales legislativas de 2003, $55 \%$ en las legislativas locales de 2004 y de $45.4 \%$ en los comicios de agosto de 2006) tiende a ubicarse por debajo de la media nacional. Para los partidos políticos, el calendario disperso desincentiva la formación de partidos fuertes, ya que cada contienda exige una labor de organización interna, la realización de campañas y la búsqueda de apoyo electoral. Además, la lógica de las elecciones noconcurrentes favorece el voto cruzado y la probabilidad de que se formen gobiernos divididos o sin mayoría.

Posiblemente, algunas de las tendencias específicas de la democratización electoral en el estado de Chiapas estén asociadas con los efectos del calendario electoral. La elección no concurrente es el factor que quizá explique mejor la singularidad de una transición en la cual se verificó la alternancia política en la gubernatura y se fortaleció el pluralismo de partidos, pero el antiguo partido hegemónico siguió actuando como un factor de equilibrio y moderación. El punto decisivo de esta transición fue la elección del 20 de agosto de 2000 que dio paso a la alternancia en el gobierno estatal y a un esquema de poder dividido. El triunfo de Pablo Salazar Mendiguchía - cuya candidatura fue respaldada por la Alianza por Chiapas integrada por PRD-PAN-PVEM-PTsignificó para el PRI una de las derrotas más sorpresivas en una entidad que había sido su bastión electoral (Tagle, 2002). Las elecciones marcaron el inicio del ciclo de desestructuración del poder unipartidista tradicional, pero no borraron del mapa político al antiguo partido hegemónico.

Bajo el nuevo escenario de pluralidad, el PRI siguió ejerciendo influencia en las instituciones relevantes. Aunque los partidos aliancistas capturaron la gubernatura, el gobernador Pablo Salazar enfrentó un esquema de gobierno dividido, en el que tuvo que cohabitar con una 
"cámara heredada" cuya composición se había decidido en la elección de 1998. En la LX Legislatura (1998-2001) del Congreso local —integrada por 40 diputados (24 uninominales y 16 plurinominales) - el PRI constituyó la mayoría con 26 escaños, mientras los partidos potencialmente aliados del gobernador únicamente controlaban 14 posiciones. ${ }^{4}$ De igual forma, en el ámbito del poder municipal el PRI disponía de un control casi hegemónico pues gobernaba en 82 de los 111 municipios.

En los comicios estatales celebrados bajo el gobierno aliancista, si bien se observa una caída en la votación por el PRI y el crecimiento de otras opciones partidistas, es claro que no logra formarse un sistema de partidos estable. En la elección local del 7 de octubre de 2001, se eligieron 24 diputados de mayoría relativa y 16 de representación proporcional y 118 presidentes municipales. Los partidos que habían formado la alianza en la elección anterior no lograron armar una sola coalición, lo cual afectó negativamente su desempeño. En los comicios para renovar el Congreso local, el PAN ganó solamente el Distrito II de Tuxtla Gutiérrez Poniente; el PRD ganó los Distritos XIV de Cintalapa y XX de Las Margaritas. Por su parte el PRI triunfó en 21 distritos, algunos de ellos ubicados en las principales ciudades ${ }^{5}$ y otros en cabeceras municipales con menor grado de urbanización y con población mayoritariamente indígena. ${ }^{6}$ En la pista de la competencia municipal el PRI arrasó en 72 municipios, el PAN ganó 12, el PRD 20, el PT 2, el PVEM 4, el PAS 2, la Alianza PRD-PT 5 y la Alianza PRD-PVEM obtuvo una alcaldía.

Tres años después, en la elección del 3 de octubre de 2004, los resultados produjeron múltiples ganadores (Sonnleitner y Viqueira, 2004). El PRI retrocedió en la competencia por los distritos locales, pues solamente obtuvo nueve victorias y dos más en alianza con el PVEM. Mientras la reconstituida Alianza por Chiapas (PRD-PANPT) conquistó trece distritos, de los cuales ocho fueron encabezados por candidatos del PRD. Por consiguiente, en la integración definitiva de la LXII Legislatura
(2004-2007) los partidos de la Alianza obtuvieron 20 diputaciones, el PRI 16, el PVEM 3 y Convergencia un solo escaño. A pesar de que ninguna de las fuerzas políticas contó con la mayoría legislativa este equilibrio ofrecía algunas ventajas para el gobernador Pablo Salazar, quien había gobernado, durante tres años, con un Congreso dominado por el PRI. Por un lado, dada esa composición de fuerzas, resultaba factible que el gobernador formará mayoría apoyándose en el bloque de partidos afines y el representante de Convergencia. Por otro lado, el gobernador podía confiar en que el Congreso local no aprobaría leyes en contra de su proyecto político.

En cuanto al reparto del poder municipal, los resultados de 2004 configuraron un escenario multipartidista. El PRI obtuvo 52 presidencias municipales, en alianza con el PVEM 3, la Alianza por Chiapas 19 alcaldías, mientras que algunas coaliciones obtuvieron unas cuantas alcaldías: PRD-PAN 3, PAN-PT l y PRD-PT 5. Por su parte, el PRD triunfó en 13 municipios, el PT en 3, el PVEM en 4 y Convergencia en 2 municipios.

Considerando las tendencias de las elecciones estatales, podemos afirmar que en el estado de Chiapas ha ido configurándose un régimen político complejo en donde distintos partidos tienen influencia en las instituciones. El cambio no ha implicado un saldo positivo para la institucionalidad de los partidos; el sistema de partidos de la entidad que había sido tradicionalmente uno de los menos plurales y competitivos pasó a ser uno de los sistemas más volátiles y fragmentados. En el año 2000 el índice del Número Efectivo de Partidos Legislativos (NEPL) en Chiapas era de 2.4, sin embargo cuatro años después figuraba entre las entidades que presentaban el mayor grado de pluralismo. Al comparar el número efectivo de partidos legislativos ${ }^{7}$ en las entidades que presentaron alguna modalidad de gobierno dividido en el año 2005, los estados de Chiapas (3.5), México (3.6), Morelos (3.8) y Tlaxcala (4), fueron las entidades con mayor pluralismo legislativo (López, 2007: 10).

Por lo anterior podemos suponer que la lógica institucional en Chiapas opera como en los regímenes 
complejos. En este tipo de equilibrios el poder institucional se divide entre múltiples partidos, puesto que los votantes tienen oportunidad de distinguir propuestas de los partidos con respecto a los diferentes temas, votar de un modo diferente para las diversas arenas políticas y dividir el gobierno entre más de uno (Colomer, 2001). Cuando en la esfera del Poder Legislativo, distintos partidos comparten el poder, la capacidad de fijar la agenda no recae en un actor unitario encargado de generar las "oleadas de legislación" y producir los resultados del proceso legislativo. El poder de agenda se reparte entre los actores institucionales y la toma de decisiones se asemeja a un proceso contingente (Przeworski, 1999).

En otros términos, un régimen complejo: a) requiere del acuerdo de los jugadores con veto (institucionales o partidarios) para producir cualquier cambio de política; b) la existencia de múltiples jugadores dificulta la implantación de cambios en las políticas públicas y contribuye a su estabilidad; y c) la toma de decisiones implica costes de negociación más altos, en la medida en que las decisiones adoptadas tienden a ser consensuales e incorporan las preferencias de múltiples actores.

\section{El procedimiento de reforma constitucional}

Durante la etapa en la que el PRI ejerció el monopolio de la representación en el estado de Chiapas tanto en el Poder Ejecutivo estatal, el Congreso y los Ayuntamientos, el proceso de reforma a la constitución fue relativamente simple y no hubo obstáculos para implantar el programa legislativo de los gobernadores. Aunque el arreglo institucional preveía un régimen de separación y equilibrio de poderes, en los hechos, el gobierno y la legislatura fueron controlados por un solo partido mayoritario y disciplinado que permitió, con cierta holgura, tomar decisiones para aprobar legislación o reformas la constitución sin enfrentar a una oposición capaz de modificar sustancialmente las iniciativas. Es cierto que esa amplia influencia de los gobernadores en la toma de decisiones y en la implantación de sus polí- ticas siempre encontró limitaciones cuando se oponían a la voluntad del Ejecutivo Federal o de la dirigencia nacional del partido.

Una de las consecuencias de la alternancia política verificada en el año 2000 es que el funcionamiento de las instituciones comenzó a operar bajo otra lógica, cuya dinámica está condicionada por los jugadores partidistas ${ }^{8}$ que controlan parcelas de poder institucional. Durante los tres primeros años de su mandato, el gobernador Pablo Salazar experimentó algunos fracasos en su intento por obtener el apoyo del Congreso para pasar ciertas piezas de legislación ordinaria. La oposición casi sistemática de la mayoría del PRI en el Congreso logró bloquear proyectos legislativos prioritarios en la agenda del gobernador.

Si la cooperación resultó difícil en la esfera legislativa, lo fue aún más en los proyectos de reforma a la constitución estatal, ya que se requirió el apoyo del Congreso y la mayoría de los municipios. Como es sabido, la Constitución del estado de Chiapas establece en el artículo 83 que el procedimiento para aprobar adiciones y reformas constitucionales exige el acuerdo de tres actores: el Congreso del estado, el Gobernador y la mayoría de los ayuntamientos. ${ }^{9}$ A diferencia del procedimiento legislativo ordinario en donde basta el acuerdo entre dos actores - el Gobernador y el Congreso- y de una mayoría absoluta de los votos. El procedimiento de reforma constitucional exige mayorías calificadas en el Congreso y la aprobación de la mitad más uno de los ayuntamientos.

Las reglas prevén el acuerdo de tres jugadores institucionales, pero evidentemente esto depende de la actuación de los jugadores partidarios con influencia en las instituciones relevantes. Por ello, al analizar el funcionamiento real de las instituciones conviene tener en cuenta el número de jugadores partidarios y sus estrategias. Dada la composición partidista del Congreso y los ayuntamientos es claro que cualquier proyecto para reformar la constitución necesariamente implica la cooperación de distintos partidos. En ese sentido, tal 
como ocurre en otros estados de la federación mexicana, la constitución en Chiapas se ha vuelto más rígida.

Adicionalmente, cuando el contenido del cambio constitucional se relaciona con aspectos sustantivos de las reglas del juego resulta más costoso negociar acuerdos. Como veremos, este es el caso de las reformas constitucionales en materia electoral que se negociaron en el estado de Chiapas. En primer lugar, ninguno de los proyectos para homologar las elecciones se elaboró detrás de un velo de la ignorancia, ${ }^{10}$ sino que el actor proponente partió de un cálculo político orientado a favorecer la acumulación del poder y beneficiar a sus potenciales aliados. En segundo, resulta interesante observar como todos los partidos coinciden y hasta consideran deseable la homologación del calendario pero difieren en las estrategias para alcanzar la reforma. Por último, podemos afirmar que el punto nodal de la disputa se localiza en los ajustes derivados de la homologación que tocan aspectos del timing político como la duración de los mandatos y la circulación de cuadros en las elecciones: ampliar o reducir los períodos para ajustar el calendario parece ser la cuestión crucial que moldea las preferencias de todos los actores.

\section{La reforma electoral del gobernador y los puntos de veto}

En el mes de octubre del año 2006 el gobernador Pablo Salazar Mendiguchía presentó ante el Congreso del estado una iniciativa de reforma constitucional cuyo objetivo central consistía en la homologación de las elecciones estatales con las federales. Para ello se propuso un paquete de reformas a los artículos 16, 36 y 61 de la Constitución Política del estado. Entre otras disposiciones, la iniciativa contemplaba - como una solución para ajustar el calendario- extender el periodo de los 118 ayuntamientos en funciones y la duración del mandato de los diputados integrantes de la LXII legislatura por un año más. De tal suerte, que al extenderse el período de la LXII Legislatura, ésta concluiría sus sesiones hasta el 15 de noviembre de 2008. En tanto que la siguiente legislatura (LXIII) sería elegida el primer domingo de julio del año 2008 y concluiría su encargo el 15 de noviembre de 2012. En cuanto a los Ayuntamientos, éstos concluirían el 31 de diciembre de 2008 y los siguientes tomarían posesión el l de enero de 2009 para terminar el 31 diciembre de 2012. La intención de estos ajustes, que por única ocasión proponían ampliar a cuatro años los períodos de las autoridades municipales y de los diputados locales en funciones era empatar las elecciones estatales con las federales previstas para el primer domingo de julio de 2012.

Las razones aducidas para promover esta iniciativa ante el Congreso local fueron las siguientes:

1. Lograr una mayor eficiencia operativa en la organización electoral local al homologar las elecciones estatales con las federales. Al efectuar en la misma fecha la elección de Gobernador del Estado, de Diputados Locales y Ayuntamientos Municipales así como las de Presidente de la República, Senadores y Diputados Federales.

2. La reducción del costo financiero de los procesos electorales y la reducción de los recursos dedicados a la formulación, ejecución y vigilancia de los comicios por parte del poder público.

3. Abrir la posibilidad de una reforma electoral integral con la creación de instituciones como Contraloría de la Legalidad Electoral y la Fiscalía Electoral.

4. Abatir el abstencionismo de la sociedad en las elecciones dado por la frecuente convocatoria a elecciones estatales y federales en tiempos diferentes.

Dada la composición de la LXII Legislatura, en donde los partidos de la Alianzapor Chiapas (PRD-PAN-PT) contaban con una casi mayoría de 20 escaños, resultaba factible construir una coalición ganadora con integrantes de otras bancadas. Así el 4 de octubre de 2006 un grupo de 
diputados ${ }^{11}$ afines al pablismo presentó ante el Congreso la iniciativa para homologar las elecciones. El proyecto recibió un tratamiento urgente pues fue presentado en primera lectura en el pleno el día 6 y tan solo unos días después fue aprobado en la sesión del ll de octubre con 27 votos a favor y 10 en contra. La iniciativa fue votada a favor por legisladores del PRD, PT, PVEM y Convergencia, mientras al interior de las bancadas del PRI y el PAN hubo votación dividida: un conjunto de diputados votaron a favor y otros diputados del PAN como Enrique Orozco González, David Corzo Castillejos, Miguel Arturo Ramírez López y Aída Ruiz Melchor y del PRI como Mariano Díaz Ochoa y Roberto Ortiz Gutiérrez votaron en contra.

Para concluir el procedimiento, el siguiente paso fue buscar la aprobación de la mayoría de los 118 cabildos del estado. Por lo que un día después de que fuera aprobada en el Congreso y en cumplimiento de lo establecido en el artículo 83 de la Constitución, noventa y ocho Ayuntamientos validaron el decreto aprobado por la LXII Legislatura. Una vez cumplido el procedimiento, el Ejecutivo publicó en el Periódico Oficial, el decreto 419 que reformaba y adicionaba el párrafo primero del artículo 16; el artículo 36 adicionándose al mismo, el párrafo segundo; y el artículo 6l de la Constitución Política del estado de Chiapas (Decreto 414, 2006).

Pese a que el Congreso había aprobado por mayoría el paquete de reformas a la constitución, a su interior surgió una corriente de opinión adversa que objetó tanto el procedimiento seguido para su aprobación como sus consecuencias políticas. Las primeras críticas a la iniciativa señalaron "graves irregularidades" en el procedimiento, al pasarse por alto la lectura en la permanente y la omisión de turnarla a la Comisión competente para su aprobación (Cuarto Poder, 11/11/2006). Entre los diputados inconformes se esgrimieron argumentos en contra de la reforma en los que se acusaba al gobernador de pretender una "reelección" enmascarada al prorrogar por cuatro años a quienes habían sido votados para permanecer solo tres años en sus cargos; favoreciendo con ello a presidentes municipales y diputados vinculados al pablismo, así como a los partidos PRD, PT y Convergencia proclives al gobernador. Incluso se puso en duda el supuesto ahorro que presumiblemente generaría la homologación y se rechazó el intento de aplicar la medida con carácter retroactivo y no para las siguientes legislaturas.

Las voces inconformes surgieron de distintos actores políticos como Holly Matus Toledo diputada federal del PRD; el líder estatal del Partido Acción Nacional, Víctor Méndez Sarmientos; el ex diputado local por el Partido del Trabajo (PT), Guilmar Sarmiento Ochoa; el obispo de la Diócesis de Tuxtla Gutiérrez; Romeo Bustamante Abadía representante de la Coordinadora Ciudadana Magisterial, el líder de la CNC Julián Nazar Morales y José Antonio Aguilar Bodegas candidato del PRI al gobierno del estado, entre otros actores.

Por su parte, la dirigencia del PAN municipal anunció que serían sancionados los diputados panistas Enrique Orozco González, David Corzo Castillejos, Miguel Arturo Ramírez López y Aída Ruiz Melchor, por haber votado a favor de la reforma electoral. Ya que como declaró un miembro de la dirigencia:

Estos diputados ya tenían la instrucción del partido de no votar a favor de la reforma porque es en sentido contrario a los intereses de la sociedad que eligió a los diputados y a los alcaldes para un período de tres años, no de cuatro, (Cuarto Poder, 23/11/2006).

Y por su parte, los diputados prístas encabezados por Mariano Díaz Ochoa anunciaron que iniciarían una acción de inconstitucionalidad ante la Suprema Corte de Justicia de la Nación.

A fin de entender el trasfondo de la inconformidad es necesario mencionar que la aprobación del proyecto de homologación ponía en jaque la celebración del proceso electoral estatal previsto para el 15 de octubre del año 2007. Las maquinarias locales de los partidos políticos se encontraban en pleno proceso interno para la selección 
de candidatos, por lo cual la propuesta de aplazar la elección por un año afectaba las oportunidades políticas de los aspirantes a ocupar cargos municipales y diputaciones locales. Además, desde la perspectiva de la sobrevivencia de los partidos, el aplazamiento de la elección impactaba también sobre la disposición de los recursos asignados por el Instituto Estatal Electoral para la realización de las campañas electorales.

Por ello la aprobación de la reforma suscitó un conflicto de intereses al interior de los partidos políticos, particularmente entre los miembros ocupantes de cargos y los aspirantes. Para los diputados y presidentes municipales en funciones, el proyecto representaba la posibilidad de obtener un beneficio a corto plazo al extender el período del cargo y quizá esta fue su motivación principal para votar a favor. En contraparte, como ya lo hemos señalado, los futuros ocupantes veían pospuestas sus aspiraciones políticas. Pero más allá de estas restricciones a la circulación de cuadros, la extensión de los mandatos también hizo aflorar las tensiones centro-periferia entre las dirigencias nacionales de los partidos y las instancias estatales.

No es azaroso que las dirigencias nacionales de los partidos políticos emprendieran las acciones más decididas para frenar la reforma. Los presidentes nacionales de los partidos Acción Nacional, Revolución Democrática, Convergencia y Revolucionario Institucional - Manuel Espino, Leonel Cota Montaño, Luis Maldonado Venegas y Mariano Palacios Alcocerpromovieron una acción de inconstitucionalidad ante la Suprema Corte de Justicia de la Nación. En dicha controversia argumentaron que las nuevas disposiciones eran violatorias tanto de la Constitución Política del Estado Mexicano como de la Constitución del Estado de Chiapas. Pero más allá del argumento sobre la constitucionalidad, la medida pretendía llamar a la disciplina a sus cuadros locales y limitar las ambiciones del gobernador.

Mientras los partidos políticos, el Gobernador y el Congreso local esperaron la resolución de la SCJN se abrió un impasse marcado por la incertidumbre en torno a la posibilidad de celebrar las elecciones programadas para octubre del $2007 \mathrm{o}$ la de proseguir con la reforma constitucional aprobada.

En el ámbito de la política local, la inconformidad ante la reforma aprobada por el Congreso local y los Ayuntamientos se manifestó en diversos conflictos municipales. La dirigencia estatal del priísmo puso a funcionar su maquinaria en los municipios indígenas y alentó la oposición hacia la reforma. Las protestas brotaron principalmente en municipios con población mayoritariamente indígena y en los cuales rigen normas tradicionales de sucesión y ejercicio de la autoridad.

En el municipio de San Juan Chamula más de dos mil priístas en asamblea de su comité y por medio de un plebiscito destituyeron al Ayuntamiento argumentando que ampliar el período a cuatro años, alteraría las normas tradicionales. En el acto, se dio un enfrentamiento entre los grupos priístas afines al presidente municipal y los priístas opositores a la reforma que derivó en la destrucción de vehículos y el saldo de varias personas lesionadas.

A raíz de estos sucesos, cerca de cien militantes priístas de las zonas indígenas y Comités Directivos Municipales del PRI demandaron al Congreso Local dar marcha atrás en la homologación de las elecciones ante la posibilidad de otros enfrentamientos en municipios indígenas como Mitontic, Larráinzar, Aldama y Santiago del Pinar. Además amenazaron con destituir a los "malos" Ayuntamientos, impedir la participación en las siguientes elecciones y avalar Consejos Municipales elegidos por las comunidades (Cuarto Poder, 19-25/11/2006). Ante estas presiones, algunos miembros del Congreso propusieron la creación de una comisión de legisladores para buscar acercamientos con las comunidades y evitar futuros enfrentamientos. Esta decisión partía del reconocimiento de que la homologación requería del consenso en estas zonas de la entidad.

A finales del mes de diciembre, la SCJN resolvió la acción de inconstitucionalidad en favor de los partidos 
políticos nacionales dando así marcha atrás a la iniciativa de reforma constitucional (Diario Oficial, 2006). El texto de la sentencia estableció la procedencia y dio por fundadas las acciones de inconstitucionalidad. ${ }^{12}$ De esta manera, un actor de la federación al ejercer su poder de veto, terminaría definiendo la disputa entre los actores políticos de la entidad.

El proceso descrito muestra el funcionamiento de los mecanismos de decisión en las instituciones y la resolución del conflicto sobre la constitucionalidad de la reforma. En primer lugar, aunque el gobernador logra superar dos instancias de veto, al obtener el apoyo del Congreso y la mayoría de los cabildos, es claro que los jugadores partidistas echaron mano de la oportunidad para impugnar desde el ámbito federal la constitucionalidad de la reforma. En segundo, la intervención de la SCJN como instancia de control de constitucionalidad, representa la acción de un jugador con veto institucional que afecta las decisiones tomadas por otras instancias; a) el contenido de la sentencia frena desde el ámbito federal, una reforma que en su proceso de aprobación había cumplido todos los procedimientos formales establecidos por la Constitución estatal; b) también invalida la pretensión de prolongar los mandatos de autoridades electas, protegiendo de esa forma los derechos de los partidos políticos frente a la parcialidad y deficiencias de las decisiones tomadas por las instituciones del gobierno estatal.

\section{El gobernador propone y luego se opone}

Con la renovación del Ejecutivo estatal en los comicios del 20 de agosto de 2006 se abrió un nuevo episodio de negociación en torno a la reforma electoral. El triunfo de Juan Sabines Guerrero, un ex militante del PRI — quien fue postulado por la Coalición por el Bien de Todos, formada por PRD-PT-Convergencia - sobre el candidato de la Alianza por Chiapas (formada por el PRI-PVEM-PANy el PANAL) José Antonio Aguilar Bodegas, puso de nueva cuenta en evidencia las debilidades de la institucionalización de los partidos (Sonnleitner, 2007: 63).
El proceso electoral se polarizó en torno a dos candidatos pertenecientes a dos sectores antagónicos de una misma familia política que aprovecharon las alianzas con diversas corrientes y facciones de partidos nacionales para armar coaliciones electorales pragmáticas. Los comicios fueron bastante reñidos y el resultado muy cerrado, pues el margen de triunfo del candidato ganador fue solo 6,282 sufragios que representaron 0.55\% de la votación (Sonnleitner, 2007: 65).

Con el fin de disipar los cuestionamientos sobre su triunfo electoral y reforzar el apoyo político de los partidos, el nuevo gobernador Juan Sabines, al cabo de unos meses de su toma de posesión, dio a conocer un proyecto para impulsar una reforma integral en materia electoral. Así en el mes de octubre de 2007 presentó ante la LXII Legislatura la iniciativa de Decreto que Reforma, Adiciona y Deroga diversas disposiciones de la Constitución Política del Estado, en materia electoral.

A diferencia de la iniciativa presentada en 2006 por el anterior gobernador Salazar Mendiguchia — que apostó por el alargamiento de los periodos de diputados locales y ayuntamientos- el nuevo proyecto se planteó justo en sentido inverso. El ajuste al calendario se realizaría acortando los períodos de funciones, ya que los diputados que serían electos para la LXIV Legislatura local y los miembros de los Ayuntamientos electos en los comicios de 2010, sólo durarían un año y ocho meses en sus cargos y esto sería por única ocasión. Gracias a este ajuste, en lo sucesivo las elecciones de diputados al Congreso y miembros de los ayuntamientos se celebrarían el primer domingo de julio del año de la elección.

Otros puntos relevantes de la reforma proponían la transformación del Instituto Estatal Electoral en Instituto de Elecciones y Participación Ciudadana, el cual se integraría por cinco consejeros electorales propietarios incluyendo al presidente, reduciendo así el tamaño del organismo que funcionaba con nueve consejeros propietarios y suplentes; este cambio debería de traducirse en un ahorro presupuestal significativo. A su vez el proyecto establecía quelos consejeros electorales del Instituto Estatal Electoral 
cesarían sus funciones el 31 de diciembre de 2007. De igual manera, el proyecto contemplaba el fortalecimiento de la Contraloría de la Legalidad ampliando sus funciones fiscalizadoras que estarían a cargo de un solo contralor que durará en su cargo siete años y no tres como se encontraba regulado; el Contralor sería nombrado por el Congreso del Estado a propuesta del Ejecutivo.

La reforma también propuso erigir al Tribunal de Justicia Electoral y Administrativa como la máxima autoridad jurisdiccional. Dicho órgano estará integrado por siete Magistrados, uno de los cuales por decisión del Pleno fungirá como su Presidente. Además, el proyecto propuso ajustar la ley electoral para ponerla en concordancia con la legislación federal en cuanto a la prohibición para la contratación de tiempos en radio y televisión. Por último, estableció el papel de los ciudadanos como responsables de la vigilancia y desarrollo de las elecciones y de la fiscalización del financiamiento público y privado; y la obligación de los partidos políticos para cumplir cuotas de género y de jóvenes en sus candidaturas, entre otros puntos.

En cuanto a los períodos de las autoridades electas el proyecto estableció que a partir del 30 de septiembre del 2012, el Congreso del estado quedaría instalado el 1 de octubre del año de la elección a fin de iniciar en esa fecha su primer periodo ordinario y concluir el 31 de diciembre; el segundo periodo ordinario iniciará el 1 de abril y terminará el 31 de julio. Los ayuntamientos tomarán posesión el 1 de octubre del año de la elección; los alcaldes, regidores y síndicos durarán en su encargo tres años y no podrán ser reelectos para el periodo inmediato. Por única ocasión los diputados de la LXIV Legislatura, electos en 2010, tomarán protesta el 16 de noviembre del año de la elección y cesarán en sus funciones el 30 de septiembre del 2012. Los integrantes de los ayuntamientos, electos el primer domingo de julio del año 2010, tomarán la protesta respectiva el día primero de enero de 2011 y cesarán en sus funciones el 30 de septiembre de 2012.
Como se desprende de lo anterior, la propuesta fue orientada a promover una reforma electoral con carácter integral que no se limitara a ajustar el calendario político. Y aunque la homologación es un punto central, el proyecto contenía una serie de regulaciones que modificaban aspectos sustantivos de la legislación electoral en Chiapas: transformar instituciones, crear nuevas funciones, acotar otras, ampliar la participación de actores en las elecciones. Desde luego su alcance se explica en gran medida por un efecto de cambio institucional inducido desde el ámbito federal; concretamente, las reformas pretendían ajustar la constitución y la legislación estatal a las modificaciones constitucionales que habían sido aprobadas por el Congreso de la Unión en septiembre de 2007 (ver Anexo).

En virtud de su alcance y profundidad, la iniciativa de reforma fue bien recibida por algunos diputados recién electos como Sami David David, quien opinó:

Me parece extraordinario, no sólo por lo que repre-
senta en las reformas de tercera generación en materia
electoral que nos van a permitir hacer menos caras
la política, menos gastos de campaña y acortar las
campañas, además de que la homologación es un viejo
reclamo de los ciudadanos chiapanecos que saben que
de un proceso a otro significa miles de millones de
pesos, señaló el priísta (Cuarto Poder, 23/10/2007).

Por su parte, el dirigente estatal del PAN, Víctor Manuel Méndez Sarmiento, también manifestó su apoyo a la iniciativa que homologaría las elecciones estatales y federales, al considerarla como un aspecto positivo y benéfico para la sociedad chiapaneca. Al mismo tiempo que invitó a las fuerzas políticas a sumarse al esfuerzo de concebir un nuevo concepto electoral para la entidad. No obstante, para el dirigente las reformas debían ir acompañadas de modificaciones al Instituto Estatal Electoral (IEE) y de dotar de mayor autonomía a la Contraloría de la Legalidad Electoral. "Lo que habría que plantear es si la Contraloría de la Legalidad Electoral 
sigue en el mismo esquema o se replantea, o bien termina siendo un órgano técnico del Consejo del Instituto Estatal Electoral" (Cuarto Poder, 23/10/2007).

Mientras que para la presidenta del Comité Ejecutivo Estatal del PRI en Chiapas, Arely Madrid Tovilla, la reforma posibilitaría que Chiapas se colocara a la vanguardia en materia electoral. El Partido del Trabajo en Chiapas, a través de su dirigente Sonia Catalina Álvarez también se pronunció a favor, resaltando el ahorro de recursos de los gastos de campaña electoral como uno de los principales objetivos de la iniciativa. Y en el mismo sentido, se manifestó el diputado local Arturo Velasco Martínez, lo mismo que el senador Manuel Velasco Coello, quien hizo un llamado a los 118 ayuntamientos para votar a favor de la iniciativa.

Bajo ese clima de opinión favorable - que de alguna manera reflejaba el consenso- - los diputados de la LXII Legislatura aprobaron la iniciativa durante su tercer periodo extraordinario de sesiones realizado el 24 de octubre de 2007. Sin embargo, después de que el Congreso local se pronunció a favor, el proceso tomó un giro sorprendente; los mismos actores que inicialmente apoyaron el proyecto modificaron su estrategia para impedir que la reforma constitucional fuera ratificada por los ayuntamientos. Dejando al lado sus preferencias reveladas en favor de la reforma, el Comité Ejecutivo Estatal del PRI actúo en sentido opuesto. Incluso en la sesión legislativa en la que se discutió y aprobó el proyecto, la presidenta estatal del PRI, Arely Madrid Tovilla, realizó llamadas a los diputados para exigirles que abandonaran el recinto legislativo y con ello reventar la sesión por falta de quórum: la solicitud no fue atendida por todos los diputados prístas y gracias a ello, se logró aprobar la reforma.

Por si quedara alguna duda sobre la nueva línea del partido, la dirigencia estatal del PRI se encaminó a dar marcha atrás a las reformas con la emisión de un comunicado de prensa al rechazar su contenido por supuestas violaciones a disposiciones constitucionales y al solicitar a sus alcaldes y regidores votar en contra de la misma. Las diferentes posturas ante el proceso de aprobación pusieron al descubierto los desacuerdos entre la dirigencia del PRI y un sector de su bancada legislativa. Contraviniendo a su dirigencia, algunos diputados priístas, como el diputado local por el distrito de Chiapa de Corzo, Tiburcio Ruiz Espinosa, exhortaron a los ayuntamientos priístas a votar a favor de la reforma aprobada por el Congreso del estado.

En respuesta a la posición del Comité Ejecutivo estatal del PRI, el gobernador Juan Sabines apostó a una estrategia desconcertante al boicotear su propia iniciativa. A través de su subsecretaria de gobierno y en una conferencia de prensa fijó su posición ante el rechazo "tajante" manifestado por el Comité Ejecutivo Nacional y el Estatal del PRI hacia la reforma electoral:

1) el gobierno del estado reconoce que toda reforma electoral debe contar con el aval de los partidos políticos; 2) el PRI se siente agredido o lastimado en sus derechos o intereses, entonces la reforma pareciera que tuviese destinatario, y aunque no es así, lo cierto es que hay un rechazo tajante de ese partido político; 3) el PRI constituye una de las fuerzas más importantes para la entidad, perfilándose como la primera fuerza en el Congreso y gobierno en más de 50 municipios, en las recientes elecciones; 4) una reforma de tal magnitud no podrá transitar plenamente si uno de los actores esta inconforme, sobre todo cuando lo que se pretende con ella es avanzar a la consolidación democrática de Chiapas (Diario de Chiapas, 26/10/2007).

De esta manera, el gobernador Sabines, a través de su secretaria de gobierno, Blanca Ruth Esponda llamó a los cabildos a votar en contra de la reforma:

(...) el Ejecutivo del Estado hace un llamado respetuoso a los honorables cabildos, particularmente a los emanados del PRI, para que no aprueben dicha reforma y así superar la amenaza de expulsión de la que han sido objeto ellos y los legisladores priistas 
que aprobaron la reforma. Con ello, el marco legal actual regirá la vida democrática de Chiapas y esta reforma quedará sin efecto (Diario de Chiapas, 26/10/2007).

Cabe suponer que detrás de la decisión —en la que el gobernador llama a votar en contra de su propio proyecto- operó un cálculo político sobre la conveniencia de posponer la discusión y aprobación de la reforma hasta que la nueva legislatura local y las autoridades municipales entraran en funciones. Con el fin de lograr una reforma que pudiera ser presentada ante la opinión pública como una acción propia del acuerdo y el consenso logrado entre los actores políticos y no como producto de la confrontación y/o imposición de un grupo. Otra posible explicación y, que se vincula con la anterior, deriva de la importancia del PRI como partido pivote, pues más allá de de la actuación de las instancias institucionales con poder de veto, lo decisivo resulta ser la postura de los dirigentes del PRI y su capacidad de actuar unitariamente al vetar la reforma.

En ese sentido, es claro que las preferencias de los diputados del PRI en el Congreso local, el Comité Directivo Estatal y su dirigencia nacional no lograron alinearse en el tema de la reforma electoral. Solo así puede entenderse que el delegado del CEN del PRI en Chiapas, Ignacio Medicutti deslindara al CEN del PRI de las acciones llevadas a cabo por la dirigencia estatal a través de Arely Madrid Tovilla. Por ello declaró que no emitieron documento alguno en contra de la reforma electoral presentada por el Ejecutivo al Congreso del estado, tampoco amenazaron a ningún priísta con la expulsión para que no votara la reforma electoral y finalmente rechazó que hubieran avalado la publicación de un comunicado de la oficina de prensa de la dirigencia nacional en contra de la reforma. Por el contrario, definió la postura del CEN como completamente distinta a la difundida por el equipo de prensa del Comité Directivo Estatal encabezado por Arely Madrid. Y afirmó que la líder nacional “...externó su respeto absoluto a la autonomía de gestión y de acción de la fracción parlamentaria del PRI en el Congreso del estado de Chiapas" (Diario de Chiapas, 29/10/2007).

Por otra parte, en el ambiente político del estado la decisión de frenar la reforma fue rechazada por diversos actores políticos. El obispo de la Diócesis de San Cristóbal, Felipe Arizmendi Esquivel, lamentó que el PRI haya "echado abajo" las reformas para homologar las elecciones en el 2012. Y declaró:

Yo no entiendo y no sé a qué se deba el retroceso, qué tipo de intereses se estén defendiendo, cuando todos estamos hablando del bien de Chiapas y de la democracia; hasta qué punto se puede pensar que esa reforma iba a perjudicar los intereses del PRI (Cuarto Poder, 29/10/2007).

Entre los miembros de la clase política también se expresó la inconformidad ante la decisión de llamar a los cabildos a votar en contra de la reforma. El diputado panista Enoch Araujo Sánchez criticó tanto al partido como al gobernador calificando de inesperadas e incomprensibles sus posturas, al echar a andar una iniciativa que después desconocerían. Por su parte, el representante del PRD ante la Contraloría de la Legalidad Electoral (CLE), Amauri Martínez Gutiérrez calificó de subversiva la postura del PRI y de irresponsable a su Comité Directivo Estatal al admitir que desconocían los términos de la reforma que antes había apoyado. Se demandaba a la líder del PRI, Beatriz Paredes Rangel, manifestar los puntos concretos de inconformidad.

Finalmente, en la votación de los ayuntamientos, ochenta y ocho cabildos rechazaron la minuta con proyecto de decreto que les fuera remitida por el Congreso estatal. Al rechazar todo el proyecto, los integrantes de los cabildos votaron en contra de la desaparición del IEE y la homologación de las fechas electorales estatales y federales. En esta ocasión, los ayuntamientos actuaron como instancia de veto para bloquear la reforma constitucional. 
Si comparamos los dos intentos por reformar la constitución y los motivos de su fracaso es posible identificar trayectorias contrastantes. El proyecto impulsado por el gobernador Pablo Salazar cumplió con el procedimiento previsto para reformar la constitución estatal -fue aprobado por el Congreso estatal y la mayoría de los cabildos - pero enfrentó la oposición de las dirigencias nacionales de los partidos y el veto de un actor federal como la Suprema Corte de Justicia de la Nación. En contraste, el proyecto del gobernador Sabines, aunque fue aprobado por el Congreso estatal, fracasó en el intento de sumar el apoyo del PRI, que en su posición de partido pivote, influyó para echar abajo la reforma y movilizar los votos de sus representantes en los cabildos que rechazaron el paquete de modificaciones a la constitución.

Indudablemente en ambos intentos se cumplió con el procedimiento establecido para reformar la constitución. Sin embargo, en el primer caso el interés de la clase política local, choca con el interés de los dirigentes nacionales de los partidos. En el segundo caso, la reforma fracasó por la falta de apoyo entre miembros de la clase política local que desde los ayuntamientos rechazaron la reforma. ¿Cuál es la lógica de estas decisiones? Si atendemos al autointerés de los políticos, es claro que la primera reforma era compatible con el autointerés de los políticos locales encargados de aprobarla: con el cambio en el statu quo, todos los políticos en funciones alargarían su período, manteniendo hasta por dos años más, el estado de preferencias expresadas en la última elección. La segunda reforma, iba en contra del autointerés inmediato de los políticos locales, pues ofrecía menores beneficios inmediatos, al mantener por un corto período el estado de preferencias que les había favorecido en la pasada elección.

\section{La reforma por consenso}

A tan solo unos días de que el proyecto fuera rechazado, el gobernador Juan Sabines en un nuevo intento, presentó el 9 de noviembre del 2007, ante el Poder Legislativo la iniciativa de decreto para reformar y adicionar diversas disposiciones de la constitución del estado de Chiapas. El mismo proyecto, que días antes había sido presentado y rechazado por el Congreso, fue presentado nuevamente en primera lectura y turnado a la Comisión de Gobernación y Puntos Constitucionales para su estudio y dictamen.

Días después, diputados integrantes de la Comisión Permanente de la LXII Legislatura local aprobaron por unanimidad la moción presentada por el gobernador Juan Sabines Guerrero para acudir al quinto periodo extraordinario de sesiones el 13 de noviembre, en donde se preveía podría quedar aprobada la nueva reforma electoral presentada por el Ejecutivo. De esta manera, por segunda ocasión en menos de un mes, diputados de la LXII Legislatura local discutirían la iniciativa de Reforma Electoral enviada por el gobernador. El tema fue incluido en las sesiones del Congreso, pero el 15 de noviembre la asamblea determinó por unanimidad retirarlo del orden del día, cancelando definitivamente la posibilidad de que la LXII legislatura aprobara la controversial iniciativa de reforma constitucional.

La LXIII legislatura (2007-2010) integrada con los resultados de la elección de octubre de 2007 entró en funciones el 15 de noviembre del mismo año. Su composición plural es reflejo de un nuevo equilibrio en donde ninguno de los partidos cuenta con la mayoría para aprobar por sí solo piezas legislativas o reformas a la constitución local: la bancada del PAN cuenta con 7 diputados, el PRI con 14, el PRD 10 legisladores, mientras el resto de los partidos obtuvo un reducido número de escaños 2 el PT, 3 el PVEM, 2 Convergencia y 2 Nueva Alianza.

Al dar inicio el primer período ordinario de sesiones al interior del Congreso local se planteó de nueva cuenta el tema de la reforma electoral. La diputada local panista, Ana Elisa López Coello reconocía la necesidad de trabajar en la iniciativa de reforma electoral, que insistía en homologar las elecciones estatales con las 
federales de 2012 y que había quedado pendiente en la legislatura anterior (Cuarto Poder, 20/11/2007).

Los miembros de la Comisión de Gobernación y Puntos Constitucionales ${ }^{13}$ de la LXIII Legislatura elaboraron un nuevo dictamen que retomó los aspectos del proyecto propuesto inicialmente por el gobernador Sabines y a finales del mes de noviembre aprobaron en lo general y en lo particular el dictamen de reforma constitucional en materia electoral. En la exposición de motivos del dictamen la Comisión determinó que:

La presente iniciativa busca garantizar un avance cualitativo en el fortalecimiento del régimen de partidos políticos y la consolidación de nuestro sistema democrático, a través del control de los recursos públicos que deberán ejercerse dentro del marco de la ley, para cumplir con las expectativas ciudadanas y con la necesidad de ajustar la política a la realidad social y económica de nuestro Estado. Así, se reducirá sustancialmente el monto de los recursos públicos destinados a las autoridades electorales, toda vez que al sustituirse a la Contraloría de la Legalidad Electoral por la Comisión de Fiscalización Electoral, que se integrará por un solo presidente, y de los Consejeros en menor número en el renovado Instituto de Elecciones y Participación Ciudadana, se reducirán los costos de manutención de dichos órganos. ${ }^{14}$

El dictamen puso en relieve los elementos novedosos en el ámbito de las reformas electorales federal y estatal que el proyecto proponía, además de incorporar las innovaciones aprobadas por el Congreso de la Unión en septiembre de 2007.

De esta manera, el día 27 de noviembre de 2007 los grupos parlamentarios (PRI, PRD, PAN, PT, PVEM, Convergencia y Nueva Alianza) del Congreso de
Chiapas aprobaron por unanimidad la minuta con proyecto de Decreto que reforma, adiciona y deroga diversas disposiciones de la Constitución Política del Estado de Chiapas..$^{15}$ Esta vez, los diputados de los partidos políticos participantes celebraron la votación, calificándola como un producto del consenso logrado entre los partidos y resaltando los avances de la reforma.

Cuadro 1

Comparativo de votaciones sobre las reformas constitucionales en materia electoral 2006-2007

\begin{tabular}{|c|c|c|c|}
\hline \multicolumn{2}{|c|}{$\begin{array}{l}\text { Votación en el Congreso sobre } \\
\quad \text { la reforma } \\
\text { del gobernador Salazar (2006) }\end{array}$} & \multicolumn{2}{|c|}{$\begin{array}{l}\text { Votación en el Congreso sobre } \\
\quad \text { la reforma } \\
\text { del gobernador Sabines (2007) }\end{array}$} \\
\hline A favor & En contra & A favor & En contra \\
\hline 27 & 10 & 38 & 0 \\
\hline
\end{tabular}

Elaboración propia con base en las Actas de Sesión.

El siguiente paso en el procedimiento legislativo consistió en remitir la documentación correspondiente a todos los Ayuntamientos para su aprobación. Esta vez la acción de los partidos se enfocó en promover el voto favorable de los ayuntamientos. Incluso algunos diputados comprometieron por anticipado el voto de los ayuntamientos gobernados por su partido. Así la presidenta de la Comisión de Equidad y Género en la LXIII Legislatura, Ana Elisa López Coello se comprometió a que el Partido Acción Nacional impulsaría la Reforma Electoral en las 16 alcaldías gobernadas por el mismo. Y como se puede observar en el siguiente cuadro, el apoyo fundamental hacia la reforma en los Ayuntamientos provino del PAN, partido que llamó a votar a favor a los integrantes de los cabildos tanto en los municipios gobernados por el PAN como en aquellos gobernados en coalición, aportando un número significativo de votos. 
Cuadro 2

Resultados de la votación sobre la reforma electoral en los Ayuntamientos del estado de Chiapas

\begin{tabular}{|c|c|c|c|}
\hline \multicolumn{2}{|c|}{$\begin{array}{c}\text { Votación en el Congreso sobre la } \\
\text { reforma } \\
\text { del gobernador Salazar (2006) }\end{array}$} & \multicolumn{2}{|c|}{$\begin{array}{l}\text { Votación en el Congreso sobre } \\
\quad \text { la reforma } \\
\text { del gobernador Sabines (2007) }\end{array}$} \\
\hline A favor & En contra & A favor & En contra \\
\hline 27 & 10 & 38 & 0 \\
\hline $\begin{array}{c}\text { Partido/ } \\
\text { coalición } \\
\text { gobernante }\end{array}$ & No aprueban* & $\begin{array}{c}\text { Partido/coalición } \\
\text { gobernante }\end{array}$ & Aprueban \\
\hline PAN & 5 & PAN & 6 \\
\hline PAN-PRD-PT & 3 & PAN-PRD-PT & 17 \\
\hline PAN-PRD & 0 & PAN-PRD & 2 \\
\hline PAN-PT & 0 & PAN-PT & 1 \\
\hline PRD & 6 & PRD & 8 \\
\hline PRD-PT & 2 & PRD-PT & 2 \\
\hline PRI & 26 & PRI & 28 \\
\hline PRI-PVEM & 2 & PRI-PVEM & 2 \\
\hline PVEM & 2 & PVEM & 1 \\
\hline PT & 3 & Convergencia & 2 \\
\hline Total & 49 & Total & 69 \\
\hline
\end{tabular}

Fuente: elaboración propia con base en Diario de Debates, noviembre 2007.

Nota* Este dato no refleja necesariamente una votación en contra sino la falta de envío del acta.

El proceso de votación en los cabildos transcurrió ágilmente y sin conflicto. El día 28, la Secretaría de Servicios Parlamentarios recibió las actas de cabildo de los ayuntamientos de la entidad. Y en la sesión ordinaria del día 29 de noviembre en la que estuvieron presentes los 40 diputados, se procedió a realizar el cómputo correspondiente. El Secretario de la Mesa Directiva, diputado Rafael Ceballos Cancino, dio lectura al comunicado que declaró la recepción de 69 actas de cabildo haciendo constar la aprobación de la Minuta Proyecto. ${ }^{16}$ Cabe resaltar que aunque se logra la mayoría necesaria para la aprobación, apenas se obtiene la aprobación de 58\% de los Ayuntamientos, hecho que revela las discrepancias que aún al final del proceso se mantenían. Y ello se constata al observar que 49 cabildos, en su mayoría gobernados por el PRI como partido único o en coalición, no enviaron voto alguno. ${ }^{17}$ Entre estos Ayuntamientos destaca el de San Cristóbal de las Casas, cuyo actual Presidente Municipal fue un férreo opositor a la reforma del gobernador Salazar, cuando se desempeñaba como diputado local.

Así, el 29 de noviembre el Congreso publicó el Decreto 004 que reforma, adiciona y deroga diversas disposiciones de la Constitución Política del Estado de Chiapas. ${ }^{18}$ Finalmente, la reforma constitucional entraría en vigor el 1 de enero de 2008 y a partir de entonces, el Poder Legislativo dispondría de seis meses para emitir el Código de Elecciones y Participación Ciudadana. Después de un año de confrontaciones se alcanzaba la aprobación de la controvertida reforma, la cual fue publicada por el gobernador Juan Sabines Guerrero en el Periódico Oficial el 29 de noviembre de 2007 (Decreto 004, 2007).

Pero, este controversial proceso de homologación electoral no concluyó definitivamente en noviembre de 2007. Recientemente, 3 de septiembre de 2008, el congreso local hizo una nueva reforma. Argumentó que en las elecciones programadas para el año 2010, el período entre el día de la elección y las tomas de protesta de diputados locales e integrantes de ayuntamientos es muy extenso. Entonces, se aprobó una nueva enmienda, que estable que por única ocasión, la elección de ese año se celebrará el primer domingo del mes de octubre. Con lo cual, se reforma el artículo segundo transitorio del decreto 004, y se establece lo siguiente:

"La elección para diputados al Congreso del Estado que integrarán la Sexagésima Cuarta Legislatura, se celebrará el primer domingo de Octubre del año dos mil diez; tomarán protesta el día dieciséis de noviembre del año de la elección y cesarán en sus funciones el día treinta de septiembre del año dos mil doce". 
"Los integrantes de los Ayuntamientos serán electos el primer domingo de Octubre del año dos mil diez; tomarán protesta respectiva del día primero de enero del año dos mil once y cesarán en sus funciones el treinta de septiembre del año dos mil doce". ${ }^{19}$

Esta nueva reforma aprobada por los diputados locales, fue a su vez remitida a los Ayuntamientos del estado y aprobada por 81 cabildos, según consta en las propias actas de los cabildos recibidos por la Secretaría de Servicios Parlamentarios.

\section{Conclusiones}

Las reformas constitucionales en materia electoral, impulsadas en Chiapas demuestran que las iniciativas que se orientaron hacia la homologación de los tiempos electorales llevaron a la movilización de los intereses de los poderes locales y activaron las tensiones institucionales. Los diferentes resultados del proceso de reforma examinados a lo largo de este trabajo permiten comprender aspectos del procedimiento de reforma constitucional y la complejidad de la toma de decisiones en contextos multipartidistas.

En el estado de Chiapas, el proceso de democratización electoral efectuado en los últimos años ha ido configurando un régimen político marcado por cierta dispersión del poder en donde distintos partidos tienen influencia en las instituciones. La influencia de jugadores partidarios en las instituciones relevantes como el Congreso y los Ayuntamientos ha modificado la lógica de las decisiones haciendo que resulte más costoso modificar unilateralmente el statu quo en materia constitucional.

Procesos como el estudiado, muestran la necesidad ineludible de concertar acuerdos entre jugadores con veto, tanto institucionales como partidarios, para lograr cambios de política. Además cuando el contenido del cambio constitucional se relaciona con aspectos sustantivos de las reglas del juego resulta más costoso negociar acuerdos. Desde luego ninguno de los proyectos para homologar las elecciones se diseñó detrás del velo de la ignorancia, tanto el actor proponente de las reformas como los jugadores partidarios consideraron primordialmente la lógica del autointerés al adoptar o rechazar nuevas reglas. En los tres casos de negociación analizados, todos los actores coinciden y hasta consideran deseable la homologación del calendario pero difieren en las estrategias para alcanzar reformas que satisfagan los diversos intereses. El aspecto que provocó los desacuerdos se ubica en los ajustes para alcanzar la homologación que tocan aspectos del timing político como la duración de los mandatos y la circulación de cuadros en las elecciones. Lo que afecta el autointerés inmediato de los políticos es la decisión de reducir o ampliar los períodos para ajustar el calendario electoral estatal con el federal.

Al comparar los tres procesos de negociación para reformar la constitución y los factores que contribuyeron al fracaso de dos proyectos y al éxito del que finalmente alcanzó a convertirse en una reforma constitucional, podemos observar diferentes resultados generados por la interacción entre el Ejecutivo, las instituciones representativas y los partidos políticos en Chiapas. La reforma impulsada por el gobernador Pablo Salazar cumplió con el procedimiento previsto para reformar la constitución estatal — fue aprobado por el Congreso estatal y la mayoría de los cabildos- pero enfrentó la oposición de las dirigencias nacionales de los partidos y el veto de un actor federal como la Suprema Corte de Justicia de la Nación.

Por su parte, el primer proyecto de reforma impulsado por el gobernador Juan Sabines, encontró obstáculos entre los actores locales. Aunque el proyecto fue aprobado por el Congreso estatal, fracasó en el intento de sumar el apoyo del PRI, que en su posición de partido pivote, influyó para echar abajo la reforma y movilizar los votos de sus representantes en los cabildos que votaron en contra del paquete de modificaciones a la constitución. El proyecto que finalmente fue exitoso y alcanzó 
el apoyo unánime de los partidos representados en las instancias institucionales, fue obra tanto de la iniciativa del gobernador Sabines, de los acuerdos entre los partidos relevantes, así como del impulso que le proporcionó la aprobación de la reforma electoral aprobada por el Congreso de la Unión en septiembre de 2007.

Durante este largo proceso de negociación en torno a las reformas constitucionales, un actor con gran capacidad de incidir fue el PRI, en particular la dirigencia estatal, la cual mostró el mayor nivel de conflicto y oposición. La fortaleza del partido quedó de manifiesto con los altos niveles de votación alcanzados en las últimas elecciones estatales (2007). Y por ello, no es de extrañar que las iniciativas presentadas, en especial la de 2006, fueran percibidas como afectación directa a sus intereses en tanto pretendían la posposición de las elecciones y pusieron en riesgo las candidaturas para las cuales se habían estado preparando. Así mismo, la oposición al proyecto del gobernador Sabines Guerrero, tuvo como base un cálculo electoral, al parecer vinculado estrechamente al asunto de las candidaturas plurinominales del PRI: los personajes de más relevancia política se verían afectados en sus aspiraciones en la siguiente legislatura, en tanto, que su estancia en el congreso tan sólo sería de veinte meses, hecho que sin duda orientó el cálculo sobre la dirigencia estatal sobre la conveniencia de apoyar o bloquear los proyectos de reforma constitucional.

Por otro lado, convendría observar que los partidos son actores que obedecen a lógicas diferentes a nivel local, estatal y federal y la actuación del PRI en todo este proceso es una muestra de ello. Lo miembros que ocupan cargos tienen intereses y estrategias divergentes de la dirigencia partidista. Desde este punto de vista no pueden ser considerados como un actor unitario y los alineamientos políticos rebasan en mucho el comportamiento partidista esperado.

Finalmente, hay que reconocer que el año de negociaciones entre los distintos actores llevó a que en materia electoral se llegara a la transición de un proyecto que planteó exclusivamente el tema de la homologación electoral, a otro finalmente aprobado, que llevó a plantear un reforma electoral integral. Hecho que sin duda, fue posible gracias al impulso federal en esta materia pero también a un proceso de acuerdo institucional suscrito por la clase política del estado de Chiapas.

\section{Notas}

${ }^{1}$ En la literatura especializada el efecto de arrastre (coattails) se refiere a la forma en que la votación en las elecciones presidenciales, así como las elecciones federales intermedias, afectan los resultados de las elecciones legislativas a nivel estatal. El partido del presidente electo tiene muchas más probabilidades de ganar un número mayor de asientos en las legislaturas estatales que de perderlos. De manera similar, el partido del presidente tiene más probabilidad de perder asientos en elecciones intermedias. Véase, (Campbell, 1986: 55).

${ }^{2}$ En el año 2000 los estados de Campeche, Colima, Guanajuato, Nuevo León, Querétaro, San Luis Potosí, Sonora, Distrito Federal, México y Morelos, celebraron comicios concurrentes con los federales. En 2003 Jalisco sincronizó su calendario y el Estado de México adoptó un calendario distinto. Durante la elección federal del 2 de julio de 2006 hubo elecciones concurrentes en diez entidades federativas en las que se eligieron al Jefe de Gobierno del Distrito Federal y a los gobernadores de Guanajuato, Jalisco y Morelos. Al mismo tiempo se disputaron las diputaciones locales y alcaldías en Campeche, Colima, Guanajuato, Jalisco, Morelos, Nuevo León, Querétaro, San Luis Potosí, Sonora, así como las diputaciones locales y las Jefaturas delegacionales en el Distrito Federal.

${ }^{3}$ El 14 de septiembre de 2007 el Congreso de la Unión aprobó una reforma constitucional en materia electoral presentada en un proyecto de decreto que reformó los artículos 6,41, 85, 108, 116 y 122 y derogó un párrafo al artículo 97 de la constitución política. La minuta fue enviada y ratificada durante el mes de noviembre por 30 Congresos estatales de la federación. 


\section{ANEXO}

\section{Cuadro comparativo sobre la Reforma electoral en Chiapas}

\begin{tabular}{|c|c|c|}
\hline \multirow[t]{2}{*}{ Texto anterior } & $\begin{array}{l}\text { Reforma propuesta en } 2006 \text { por el } \\
\text { Gobernador Salazar Mendiguchia }\end{array}$ & $\begin{array}{l}\text { Reforma propuesta en } 2007 \text { por el } \\
\text { Gobernador Sabines Guerrero }\end{array}$ \\
\hline & $\begin{array}{l}\text { Se reforma y adiciona el párrafo prim- } \\
\text { ero del artículo 16; reforma el artículo } \\
36 \text { adicionándose al mismo, el párrafo } \\
\text { segundo; y reforma el artículo } 61 \text { de la } \\
\text { Constitución Política del Estado. }\end{array}$ & $\begin{array}{l}\text { Se reforma la denominación del título tercero y se adicionan al mismo título, el } \\
\text { capítulo 1, denominado "De los poderes públicos" y el capítulo II, denominado "De } \\
\text { las elecciones", se adiciona el artículo } 14 \text { Bis; se reforma el inciso a) de la fracción } \\
\text { II del artículo 18, se deroga el artículo 19; se reforma el artículo 22; se reforma la } \\
\text { fracción XLVII, del artículo 29; se reforma el artículo 61; se reforma el artículo 69; se } \\
\text { reforma el párrafo primero del artículo 71; se reforma el párrafo primero del artículo } \\
\text { 72; se adiciona el artículo 76Bis; y se reforma el primer párrafo del artículo 79, de la } \\
\text { Constitución Política del Estado de Chiapas }\end{array}$ \\
\hline $\begin{array}{l}\text { Art. 16. El Congreso del } \\
\text { Estado se integra con } \\
\text { Diputados electos en } \\
\text { su totalidad cada tres } \\
\text { años. Por cada Diputado } \\
\text { Propietario se elegirá un } \\
\text { Suplente. }\end{array}$ & $\begin{array}{l}\text { Se añade: la elección de diputados se } \\
\text { verificará el primer domingo de julio } \\
\text { del año de la elección. }\end{array}$ & $\begin{array}{l}\text { Art. } 14 \text { bis. Las elecciones de diputados al Congreso y miembros de ayuntamien- } \\
\text { tos del Estado, se celebrarán el primer domingo de julio del año de la elección. } \\
\text { La actuación de los poderes públicos durante procesos electorales será imparcial } \\
\text { (...) } \\
\text { Las autoridades municipales, estatales y federales cesarán la difusión pública de } \\
\text { obras y programas durante las campañas electorales (...) }\end{array}$ \\
\hline $\begin{array}{l}\text { Art. } 36 \text {. El Gobernador } \\
\text { electo por sufragio } \\
\text { popular en elecciones } \\
\text { ordinarias entrará a } \\
\text { ejercer su cargo el } 8 \text { de } \\
\text { diciembre y durará en él } \\
6 \text { años. }\end{array}$ & $\begin{array}{l}\text { Se añade: Las elecciones ordinarias } \\
\text { para Gobernador, a que se refiere el } \\
\text { párrafo anterior, se llevarán a cabo } \\
\text { el mismo día en que se efectúen } \\
\text { las elecciones ordinarias para elegir } \\
\text { Presidente de los Estados Unidos } \\
\text { Mexicanos." }\end{array}$ & $\begin{array}{l}\text { Apartado A. De los ciudadanos chiapanecos } \\
\text { Los ciudadanos participarán en la vigilancia, preparación y desarrollo de los proce- } \\
\text { sos electorales ordinarios y extraordinarios, así como en la fiscalización del origen, } \\
\text { uso, aplicación y destino del financiamiento público y privado de los partidos } \\
\text { políticos (...) }\end{array}$ \\
\hline \multirow[t]{4}{*}{$\begin{array}{l}\text { "Artículo 61. (...) } \\
\text { Los Ayuntamientos } \\
\text { deberán tomar posesión } \\
\text { el día primero de enero, } \\
\text { siguiente a su elección. }\end{array}$} & $\begin{array}{l}\text { Los Ayuntamientos deberán tomar } \\
\text { posesión el día primero de enero } \\
\text { siguiente al de su elección. Las elec- } \\
\text { ciones ordinarias, para elegir a los } \\
\text { miembros de los Ayuntamientos antes } \\
\text { mencionados, se llevarán a cabo el } \\
\text { primer domingo de julio del año de la } \\
\text { elección. }\end{array}$ & $\begin{array}{l}\text { Apartado B. De los Partidos Políticos } \\
\text { Los partidos políticos deben incluir entre sus candidatos propietarios a diputados al Con- } \\
\text { greso del Estado y a integrantes de los ayuntamientos a no más del setenta por ciento de } \\
\text { un solo sexo y no menos del treinta por ciento de jóvenes menores de treinta años. } \\
\text { (...) } \\
\text { Así mismo, en las zonas con predominancia en población indígena, los partidos políti- } \\
\text { cos podrán registrar preferentemente candidatos de origen indígena. } \\
\text { La campaña de gobernador no podrá exceder de noventa días; la de diputados al } \\
\text { Congreso del Estado y la de miembros de los Ayuntamientos, de sesenta días. }\end{array}$ \\
\hline & & $\begin{array}{l}\text { La calificación de las elecciones estará a cargo del Instituto de Elecciones y Par- } \\
\text { ticipación Ciudadana y el Tribunal de Justicia Electoral y Administrativa del Poder } \\
\text { Judicial del Estado. } \\
\text { Será el único responsable de la preparación y organización de los procesos elector- } \\
\text { ales estatales, municipales y de los relacionados con las consultas ciudadanas. (....) } \\
\text { El Consejo General (...) Estará integrado por un consejero presidente y cuatro con- } \\
\text { sejeros electorales con voz y voto. Concurrirán con voz pero sin voto a las Sesiones } \\
\text { los representantes de los partidos políticos y un secretario ejecutivo. } \\
\text { El Consejero Presidente y los Consejeros Electorales (...), serán nombrados por } \\
\text { el Congreso del Estado (...). Durarán en el cargo siete año y podrán ser reelectos } \\
\text { para otro período igual. }\end{array}$ \\
\hline & & $\begin{array}{l}\text { La Comisión de Fiscalización Electoral, será el órgano del Estado de Chiapas (...) } \\
\text { responsable de vigilar y fiscalizar, los gastos de precampañas, campañas elector- } \\
\text { ales, la transparencia y fiscalización del financiamiento de los partidos (...) } \\
\text { Estará a cargo de un Presidente, quien durará en su cargo siete años y será nomb- } \\
\text { rado por el Congreso del Estado (...) }\end{array}$ \\
\hline & & $\begin{array}{l}\text { El Tribunal de Justicia Electoral y Administrativa (...) Es la máxima autoridad juris- } \\
\text { diccional en las materias electoral y administrativa (...) Estará integrado por siete } \\
\text { magistrados. }\end{array}$ \\
\hline
\end{tabular}


LA DISPUTA POR LA HOMOLOGACIÓN

\begin{tabular}{|c|c|c|}
\hline & & $\begin{array}{l}\text { Art. } 22 \text { El Congreso del Estado deberá quedar instalado el } 1 \text { de octubre del año de } \\
\text { elección, debiendo iniciar su } 1 \text { período ordinario de sesiones ese mismo día de ese } \\
\text { mismo mes, terminando el } 31 \text { de diciembre, y el } 2 \text { período ordinario iniciará el } 1 \text { de } \\
\text { abril, terminando el } 31 \text { de julio (...) }\end{array}$ \\
\hline & & $\begin{array}{l}\text { Art. 61. Los ayuntamientos deberán tomar posesión el día primero de octubre, año } \\
\text { de la elección; los presidentes municipales, regidores y síndicos de los ayun- } \\
\text { tamientos, electos popularmente por elección directa, durarán en su cargo tres } \\
\text { años y no podrán ser reelectos para el período inmediato. }\end{array}$ \\
\hline & $\begin{array}{l}\text { Transitorios: } \\
\text { Artículo Tercero. Para los efectos de la } \\
\text { presente Reforma Constitucional, los } \\
\text { Diputados miembros de la Sexagésima } \\
\text { Segunda Legislatura del Congreso } \\
\text { del Estado, concluirán sus funciones } \\
\text { legislativas, por única vez, el día } 15 \text { de } \\
\text { noviembre del año } 2008 . " \\
\text { "Artículo Cuarto. Los Diputados } \\
\text { integrantes de la Sexagésima Tercera } \\
\text { Legislatura del Congreso del Estado, } \\
\text { serán electos el primer domingo de julio } \\
\text { del año } 2008 \text { y, por única vez, durarán } \\
\text { en su encargo cuatro años, iniciando } \\
\text { sus funciones legislativas el día } 16 \text { de } \\
\text { noviembre del } 2008, \text { para concluir el día } \\
\text { 15 de noviembre del año } 2012 . " \\
\text { "Artículo Quinto. Para los efectos de la } \\
\text { presente Reforma Constitucional, los mi- } \\
\text { embros de los Ayuntamientos actuales, } \\
\text { por única vez, concluirán su encargo, el } \\
\text { día } 31 \text { de diciembre del año } 2008 . " \\
\text { "Artículo Sexto. Los integrantes de los } \\
\text { Ayuntamientos que tomen posesión } \\
\text { el día primero de enero del año } 2009 \text {, } \\
\text { serán electos el primer domingo del } \\
\text { mes de julio del año } 2008, \text { y por única } \\
\text { vez, durarán en su encargo cuatro años, } \\
\text { para concluir el día } 31 \text { de diciembre del } \\
\text { año } 2012 . "\end{array}$ & $\begin{array}{l}\text { Transitorios: } \\
\text { Primero. El decreto entrará en vigencia el día } 1 \text { de enero de } 2008 \text { (...) } \\
\text { Las reformas de los artículos } 22 \text { y } 61 \text { (...) entrarán en vigencia a partir del } 30 \text { de } \\
\text { septiembre del } 2012 . \\
\text { Segundo. Como excepción a lo dispuesto por los artículos } 16 \text { y } 61 \text { (...), por única } \\
\text { ocasión: } \\
\text { a) Los diputados del Congreso del Estado que integrarán la Sexagésima } \\
\text { Cuarta Legislatura, que resulten electos en la elección del año dos mil diez, } \\
\text { tomarán protesta el día dieciséis de noviembre del año de la elección y cesarán de } \\
\text { sus funciones el día treinta de septiembre del año dos mil doce. } \\
\text { b) Los integrantes de los ayuntamientos que sean electos el primer } \\
\text { domingo de julio del año dos mil diez, tomarán la protesta respectiva el día primero } \\
\text { de enero del año dos mil once y cesarán en sus funciones el treinta de septiembre } \\
\text { de dos mil doce. } \\
\text { Tercero: Se extingue el Instituto Estatal Electoral (...) } \\
\text { Quinto: Se extingue la Contraloría de la Legalidad Electoral (...) } \\
\text { Séptimo: Dentro de un término que no exceda de seis meses (...) el Congreso del } \\
\text { Estado deberá expedir el Código de Elecciones y Participación Ciudadana. } \\
\text { Dentro del Código (...) , se regulará la estructura y operación de la Comisión de } \\
\text { Fiscalización Electoral. }\end{array}$ \\
\hline
\end{tabular}

Nota: Elaboración propia en la que se hace una síntesis de los aspectos considerados como más significativos de las propuestas de reforma constitucional con base en Decreto 419, Periódico Oficial, Tomo II, Tuxtla Gutiérrez, Chiapas, 14 de octubre de 2006, número 389. Decreto No. 004, Periódico Oficial, tomo III, Tuxtla Gutiérrez, Chiapas, México, 29 de noviembre de 2007, No. 065 
La reforma al artículo 116 incluyó una mención específica relativa a la homologación de los calendarios electorales en las entidades federativas, por la cual se establece que las constituciones y leyes electorales de los estados que no celebran elecciones concurrentes hagan ajustes para que sus comicios se celebren el primer domingo de julio del año que corresponda. Si bien el artículo 116 excluyó de la obligación de ajustar sus calendarios a los estados cuyas elecciones para gobernador se celebren en el mismo años de los comicios federales y no coincidan en la misma fecha de la jornada federal (Reyes, 2007: 19)

${ }^{4}$ Las bancadas del PRD con 5 diputados, el PAN 5, el PT 2, Partido del Frente Cívico l (PFC) y un diputado independiente.

${ }^{5}$ Como los Distritos I (Tuxtla Gutiérrez Oriente), III (Chiapas de Corzo), IV (Venustiano Carranza), V (San Cristóbal de Las Casas), VI (Comitán), VII (Ocosingo), XVIII (Tapachula Norte), XIX (Tapachula Sur).

${ }^{6}$ Tal es el caso de los distritos XXI (Tenejapa), XXII (Chamula), XXIII y X (Bochil).

${ }^{7}$ El índice del número efectivo de partidos legislativos (NEPL) resulta de una ponderación del tamaño relativo de los partidos representados en la legislatura. Se calculó mediante la fórmula de Laakso y Taagepera (1979), $\mathrm{NEPL}=1 / \sum e_{i}^{2}$, en donde ei, equivale la proporción de asientos de cada partido en la legislatura.

${ }^{8}$ De acuerdo con Tsebelis los jugadores con veto partidarios son aquellos generados por el juego político dentro de las instituciones. Se trata de las interacciones entre los partidos en el marco de las instituciones y sus oportunidades de controlar una coalición ganadora que derrote al status quo (Tsebelis, 2006: 105).

${ }^{9}$ Para que una propuesta de reforma constitucional entre en vigor se requiere que el proyecto sea aprobado por una mayoría calificada del Congreso, su publicación en el período oficial del Estado y que la mayoría de los ayuntamientos den su aprobación dentro de los 30 días siguientes a aquel en que se hubiere comunicado sobre el proyecto de reformas $\mathrm{y} / \mathrm{o}$ adiciones, entendiéndose que su abstención es aprobación (Constitución Política, art. 83).
${ }^{10}$ Esta expresión se encuentra en la obra de John Rawls para quien la metáfora del velo de la ignorancia forma parte de una de las precondiciones de los convenios justos. Si las partes desconocen su posición política, distribución de talento, riqueza o fuerza, no podrán reformar las reglas de acuerdo a su propia situación o atendiendo a sus intereses especiales. El velo de la ignorancia cubre todas las informaciones que podrían tener las personas y que afectan el diseño de reglas imparciales y justas. Véase, (Rawls, 1985: 164-165)

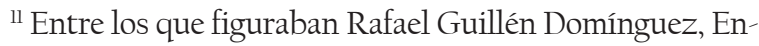
rique Orozco González, Roberto W. Ortiz Gutiérrez, Flor de María Coello Trejo, Carlos Raymundo Toledo y Arturo Velasco Martínez.

${ }^{12}$ Por lo expuesto y fundado, se resuelve: Primero. Son parcialmente procedentes y fundadas las acciones de inconstitucionalidad acumuladas a que este expediente se refiere. Segundo. Con la salvedad a que se refiere el siguiente punto resolutivo, se sobresee en relación con los artículos 16, 36 y 61 de la Constitución Política del Estado de Chiapas, reformados mediante el Decreto 419 publicado el catorce de octubre de dos mil seis en el Periódico Oficial de ese Estado. Tercero. Se reconoce la validez de los artículos 16, párrafo primero y 6l, párrafo segundo, de la Constitución Política del Estado de Chiapas, reformados mediante el Decreto 419 publicado el catorce de octubre de dos mil seis en el Periódico Oficial de ese Estado, únicamente en cuanto a la porción normativa que en ambos preceptos legales se establece en los siguiente términos: "...primer domingo de julio del año de la elección". Cuarto. Para los efectos precisados en el penúltimo considerando de esta ejecutoria, se declara la invalidez de los artículos Segundo a Sexto transitorios del citado Decreto 419, así como la del artículo Primero transitorio del mismo Decreto, exclusivamente en relación con la vigencia que dio a la porción normativa a que se refiere el punto resolutivo anterior. Quinto. Publíquese esta ejecutoria en el Diario Oficial de la Federación, en el Semanario Judicial de la Federación y su Gaceta, así como en el Periódico Oficial del Estado de Chiapas, Sentencia relati- 
va a la Acción de Inconstitucionalidad 47/2006 y sus acumuladas 49/2006, 50/2006 y 51/2006, promovidas por los partidos políticos Acción Nacional, de la Revolución Democrática, Convergencia y Revolucionario Institucional, publicado en el Diario Oficial de la Federación el 26 de diciembre de 2006.

${ }^{13}$ Esta Comisión se integró por los diputados: José Ángel Córdova Toledo, Presidente; Sergio Lobato García, Vicepresidente; Ovidio Cortazar Ramos, Secretario y como vocales Juan Carlos López Fernández, Horacio Domínguez Castellanos, Miguel Ángel Vargas Blanco y Mateo Guzmán López.

14 Dictamen de la Comisión de Gobernación y Puntos Constitucionales, Sexagésima Tercera Legislatura, H. Congreso del estado Libre y Soberano de Chiapas, 26 de noviembre de 2007, p. 2.

${ }^{15}$ La minuta fue publicada el mismo día, en el periódico oficial número 063 tomo III para conocimiento de los Ayuntamientos.

${ }^{16}$ Los municipios, que en esta ocasión aprobaron la iniciativa fueron: Amatán, Amatenango de la Frontera, Amatenango del Valle, Ángel Albino Corzo, Arriaga, Bejucal de Ocampo, Bella Vista, Berriozábal, Bochil, Catazajá, Chapultenango, Chiapa de Corzo, Chiapilla, Chicoasén, Chicomuselo, Coapilla, Copainalá, El Bosque, El Porvenir, Frontera Comalapa, Frontera Hidalgo, Huehuetán, Ixhuatán, Ixtacomitán, Ixtapangajoya, Jiquipilas, Juárez, La Concordia, La Grandeza, La Trinitaria, Mapastepec, Mazapa de Madero, Metapa de Domínguez, Montecristo de Guerrero, Motozintla, Nicolás Ruiz, Ocotepec, Ocozocoautla de Espinosa, Ostuacán, Osumacinta, Pantepec, Pichucalco, Pueblo Nuevo Solistahuacán, Rayón, Reforma, Sabanilla, Salto de Agua, San Fernando, San Juan Cancuc, San Lucas, Socoltenango, Solosuchiapa, Soyaló, Suchiapa, Tapalapa, Tecpatán, Teopisca, Tila, Tonalá, Totolapa, Tumbalá, Tuxtla Gutiérrez, Tuxtla Chico, Tzimol, Unión Juárez, Villa Corzo, Villaflores, Yajalón y Zinacantán.

${ }^{17}$ Como un ejemplo de las dificultades que a nivel local, representan procesos como el analizado, mostramos la respuesta del Presidente Municipal priista de Larrainzar al
Congreso local, quien informa sobre la no aprobación de la reforma, explicando lo siguiente “... por respeto a nuestros usos y costumbres de este municipio no fue aprobado, razones por el cual quieren seguir manteniendo la forma de elegir nuestras autoridades como se ha venido realizando desde años atrás. Al respetar esto, se mantendrá una tranquilidad y paz social en el municipio. De antemano saben ustedes que la presidencia municipal esta al poder de la autoridad autónoma en rebeldía (zapatistas) y solicitamos encarecidamente que nos respete nuestras peticiones" (sic), Documento que envía el Presidente Municipal Constitucional, Diego Hernández Ruíz al Congreso del Estado de Chiapas, 2 de diciembre del 2007.

${ }^{18}$ Artículo Único. Se reforma la denominación del Título Tercero y se adicionan al mismo Título, el Capítulo I denominado "De los Poderes Públicos" y el Capítulo II denominado "De las Elecciones"; se adiciona el artículo 14 Bis; se reforma el inciso a) de la fracción II del artículo 18, se deroga el artículo 19; se reforma el artículo 22; se reforma la fracción XLVII, del artículo 29; se reforma el artículo 6l; se reforma el artículo 69; se reforma el párrafo primero del artículo 7l; se reforma el párrafo primero del artículo 72; se adiciona el artículo 76 Bis; y se reforma el primer párrafo del artículo 79, de la Constitución Política del Estado de Chiapas. Decreto No. 004, Por el que se reforma, adiciona y deroga diversas disposiciones de la Constitución Política del Estado de Chiapas, H. Congreso, Estado Libre y Soberano de Chiapas, Sexagésima Tercera Legislatura, 29 de noviembre de 2007, p. 6.

${ }^{19}$ Decreto por el que se reforma el Articulo Segundo Transitorio del Decreto número 004, de fecha 29 de noviembre de 2007, que Reforma, Adiciona y Deroga diversas disposiciones de la Constitución Política del Estado de Chiapas, Congreso del Estado Libre y Soberano de Chiapas, 3 de septiembre de 2008.

\section{Bibliografía}

Campbell, James E., 1986, "Presidential Coattails and Midterm Losses in State Legislative Elections", en American Political Science Review, vol. 80, pp. 45-83. 
Colomer, Josep M., 2001, Instituciones Políticas, editorial Ariel.

Decreto 419 que reforma y adiciona el párrafo primero del artículo 16; reforma el artículo 36 adicionándose al mismo, el párrafo segundo; y reforma el artículo 61 de la Constitución Política del Estado Libre y Soberano de Chiapas, Periódico Oficial, tomo II, Tuxtla Gutiérrez, Chiapas, sábado 14 de octubre de 2006, núm. 389.

Decreto No. 004, Por el que se reforma, adiciona y deroga diversas disposiciones de la Constitución Política del Estado de Chiapas, Periódico Oficial del Estado libre y Soberano de Chiapas, tomo III, Tuxtla Gutiérrez, Chiapas, México, jueves 29 de noviembre de 2007, núm. 065.

Decreto No. 237, Por el que se reforma el Articulo Segundo Transitorio del Decreto número 004, de fecha 29 de noviembre de 2007, que Reforma, Adiciona y Deroga diversas disposiciones de la Constitución Política del Estado de Chiapas, Congreso del Estado Libre y Soberano de Chiapas, Tuxtla Gutiérrez, Chiapas, 3 de septiembre de 2008.

Diario Oficial de la Federación el 26 de diciembre de 2006, Sentencia relativa a la Acción de Inconstitucionalidad 47/2006 y sus acumuladas 49/2006, 50/2006 y 51/2006, promovidas por los partidos políticos Acción Nacional, de la Revolución Democrática, Convergencia y Revolucionario Institucional.

Dictamen de la Comisión de Gobernación y Puntos Constitucionales, Sexagésima Tercera Legislatura, H. Congreso del estado Libre y Soberano de Chiapas, 26 de noviembre de 2007, p. 2.

Gómez Tagle, Silvia, 2002, "Chiapas: democracia y lucha indígena”, en Manuel Alcántara (Ed.) Política en América Latina, I Congreso Latinoamericano de Ciencia Política, Ediciones de la Universidad de Salamanca, pp. 2080-2112.

Laakso, Markku, y Rein Taagapera, 1979, "Effective Number of Parties: A Measure with application to West Europe", en Comparative Political Studies, vol. 12, núm. 1, pp. 3-27.

López Lara, Álvaro F, 2007, ¿Gobierno dividido o gobierno compartido? Multipartidismo y coaliciones en las legislaturas locales de México", ponencia preparada para el XXVII Congreso, Latin American Studies Association, Montreal, Canadá, 5-8 de septiembre.

Peschard, Jaqueline, 2004, "Presentación en el panel Sistemas electorales y perspectivas", en La construcción del federalismo argentino: perspectivas comparadas, Buenos Aires, Programa de las Naciones Unidas para el Desarrollo, http:/www.desarrollohumano.org.ar/download/VersiónPDFLibro.pdf.

Przeworski,Adam, 1999, "La democracia como resultado contingente de conflictos", en Jon Elster y Rune Slagstad, Constitucionalismo y Democracia, México, Fondo de Cultura Económica, pp. 89-90.

Rawls, John, 1985, Teoría de la justicia, México, Fondo de Cultura Económica.

Reyes Tépach, 2007, La homologación de los calendarios electorales en las entidades federativas de México en los términos de la reforma al artículo 116 constitucional, Servicios de Investigación y Análisis, Cámara de Diputados LX Legislatura, noviembre de 2007, http://www.diputados. gob.mx/cedia/sia/se/SE-ISS-28-07.pdf.

Sonnleitner, Willibald y Juan Pedro Viqueira, 2004, "Elecciones en Chiapas: Todos ganan", en Revista Nexos, núm. 23, noviembre.

Sonnleitner, Willibald, 2007, "La nueva geografía electoral de Chiapas: polarización política, fragmentación partidista e incertidumbre electoral", en LiminaR. Estudios sociales y humanísticos, año 5, vol. V, núm. 1, junio, pp. $60-76$

Tsebelis, George, 2006, Jugadores con veto. Cómo funcionan las instituciones políticas, México, Fondo de Cultura Económica.

Vergara Santana, Martha, 2007, "Elecciones concurrentes: diversidad y unidad", en Cortés Guardado, Marco Antonio y Víctor Alejandro Espinoza Valle, Elecciones concurrentes en México. Competencia, participación y voto diferenciado, México, Universidad de Guadalajara, Ediciones Eón. 